\title{
Reproductive Females of the Kura (Persian) Sturgeon (Acipenser Persicus Borodin, 1898) Raised "From Eggs" in the Hatchery of Azerbaijan
}

\section{Chingiz $\mathbf{M}^{*}$ \\ Baku State University, Azerbaijan}

*Corresponding author: Chingiz Mamedov, Baku State University, Az1141, 23, Z. Xalilov Street, Baku, Azerbaijan, Tel: +994125390294; Email: m_chingiz@yahoo.com

\section{Research Article}

Volume 3 Issue 1

Received Date: December 17, 2018

Published Date: April 18, 2019

DOI: $10.23880 /$ jenr- 16000157

\section{Abstract}

The reproduction stock of various species of sturgeons in the conditions of the aquaculture of Azerbaijan on the basis of Khylly Sturgeon Fish Farm was formed on the basis of the young fish of artificial generation which total quantity is equal to more than 5000 individuals. For the first time in the sturgeon-breeding history of Azerbaijan sex and maturity of various species grown in aquaculture condition was determined by the method of ultrasound examination. 67\% (47 pieces) of examined fish (70 pieces) was Persian (Kura) sturgeon. Most of them 59.6\% ( $\hat{-}-28$ and q-19) were males. Among the analyzed Persian (Kura) sturgeon fish the species at II maturity stage ( $\widehat{\delta}-16$ and $q-10$ ) was dominant. In 2013 the reproductive females of the Persian (Kura) sturgeon reared "from eggs" in the fish cultural practices of Azerbaijan for the first time were used under the hatchery conditions. The aim of the present study is a comparative evaluation of the quality of reproductive females holding under the conditions of sturgeon hatcheries and obtaining their off spring. This research is also needed to develop scientifically substantiated documents on exploitation of sturgeon broodstocks on the basis of sturgeon hatcheries of Azerbaijan.

Keywords: Broodstock; Ultrasound; Reproductive Females; Acipenser Persicus "from eggs"; Sturgeon hatchery

\section{Introduction}

The sturgeon (Acipenseriformes) group is an ancient and unique group of cartilage hanoids. At present, there are 25 species of sturgeon (Acipenseridae) in the world $[1,2]$. Six of them live the Caspian Sea. Since the meat and caviar of the sturgeons have a high commercial value theirs resources in the nature have dropped dramatically due to hunting over norm for many years, the construction of dams on the rivers where they have been migrating at reproduction, the anthropogenic pollution of the Caspian Sea and for other reasons. All types of livestock living in the Caspian basin have been included in Annex I and II of the CITES Convention (The Convention on International Trade in Endangered Species of Wild Fauna and Flora) since 1998, and all other species except the 2 species are included in various categories of the International Red Book (IUCN - The International Union for Conservation of Nature. One species (A. nudiventris) is included in the "Red Book" of the Republic of Azerbaijan. 
Because of the sharp decline of the resources in the Caspian Sea, sturgeon hatcheries are not provided by enough productive individuals in our Republic and in other Caspian littoral countries, resulting in a decrease in the number of sturgeon fries annually released from the hatcheries to the natural water basins. Increase of sturgeon resources and reproduction is only possible by improving their hatchery breeding technologies and applying more modern methods.

Azerbaijan is the cradle of the world's sturgeon growing, which transformed into a highly productive fish farming industry until now. It is on the Kura River in 1954 the world's first Sturgeon Hatchery was built, which was a experimental project, as it became the result of scientific experiments of outstanding researchers. At this plant almost all questions on artificial breeding and rearing of different species of sturgeon were clarified. This plant was a recognized school for sturgeon growers not only of the former Soviet Union, but also in many other countries. Thanks to the development of local scientists in the 60 s of the last century the system of plants for the breeding of sturgeon, which produced bred juveniles in natural waters, was built.

In the last years of the XX and early XXI century, a sharp decline in industrial scale reproduction of sturgeon in the Caspian region was observed. The main reason for the decline of the scale of the artificial reproduction of sturgeon fish breeding is the lack of fish-quality producers in the sturgeon hatcheries $(\mathrm{SH})$. In this regard, the formation of the reproductive school of sturgeon in the factory based on artificial fish generation and natural complex is a priority direction for modern sturgeon growing. This measure is an alternative way to preserve biological diversity of sturgeon and guaranteed reproduction of juveniles for release in a natural body of water in case of an insufficient number of prepared producers [3-8].

In Azerbaijan the formation of recovery-maternal stock of sturgeon fish has been carrying out since 2004 year and breeding of fish from the stage of larvae till the adult conditions is fulfilled by using of pool method $[9,8]$. Formation of recovery-maternal stock of sturgeon fish «from roe» assumes long growing of fish industrially. Meanwhile it is known that quality of a breeding material in many respects depends on conditions of their maintenance [9-11]. Considering that the morphological analysis of blood is one of delicate and objective methods of an estimation of a physiological condition of an organism Ivanova (1983) [12], we have previously studied the fish breeding and biological and hematological parameters of individuals of different ages Persian (Kura) sturgeon in the course of their long-term breeding in captivity. Obtained results allowed to the come to a conclusion that the functional development of the Persian sturgeon fry in the hatchery runs without noticeable deviations from the physiological norm $[10,11]$.

Definition of the sex and maturity stage at sturgeon grown in aquaculture conditions at early ages and in the reproductive runs of various age groups by using the noninvasive diagnostic methods (ultrasound) and using them depending on development stages for fish growing purposes are one of the urgent matters.

The aim of the present study is a comparative evaluation of the quality of reproductive females holding under the conditions of sturgeon hatcheries and obtaining their off spring. This research is also needed to develop scientifically substantiated documents on exploitation of sturgeon broodstocks on the basis of sturgeon hatcheries of Azerbaijan.

\section{Materials and Methods}

Study on the formation of brood stock sturgeon "from roe" under Khylly Sturgeon Fish Farm of Azerbaijan has an experimental nature. To ascertain compliance of morphometric parameters of different age fish with breeding criteria used in the selection of a broodstock, their morphological and biological evaluation was performed. As the main indicators in the selection, the mass of fish (W, g, kg), the overall biological length (L,sm) and coefficient of fatness on Fulton $(\mathrm{F}, \mathrm{u})$ were used. These indicators are the main criteria for quality assessment of pedigree fish and associated with weight and species characteristics of farmed fish.

The study was conducted by us in April 2012 at Khylly Sturgeon Fish Farm of Azerbaijan within the framework of the regional training project "The formation of sturgeon-getter, using them and ultrasound definition of their sex" of the UN Food and Agriculture Organization (FAO). Ultrasound examination was carried out in repairgetter Persian (Kura) sturgeon (Acipenser persicus) formed since 2004, in the Russian sturgeons (A. gueldenstaedtii) formed in 2005, in the Russian and Siberian sturgeon hybrids (A. gueldenstaedtii x A. baerii), sterlet (A. ruthenus) and beluga (Huso huso) fishes, as well as on part of starred sturgeon (A. stellatus) formed in 2006, and their sex and maturity stages were determined. The total number of repair-getter sturgeon fishes 


\section{Journal of Ecology \& Natural Resources}

examined was 70 pcs. The "Mindray DP-6600" device was used at ultrasound examination. Methods of research works and required recommendations have been described in details in the scientific literature [4].

Works on the production of off spring/fry from reproductive females carried out in 2013. To stimulate maturation of selected two elite females of the Persian (Kura) sturgeon (Acipenser persicus Borodin) of the generation 2004 from hatchery - reared broodstock intramuscularly was injected by the suspension of acetone-water extract of sturgeon pituitaries based on the rate of $2.5 \mathrm{mg}$ per $1 \mathrm{~kg}$ of body weight. To avoid inbreeding with the view of insemination eggs two males of Persian (Kura) sturgeon of the generation 2005 from hatchery were used. Ultrasound diagnosis of sex and maturity stages, hormonal stimulation of breeders, fertilization and de-adhesion of eggs (unsticking), as well as its incubation in the "Osetr" incubation system were conducted according to the existing method $[13,4,8]$.

The entire biotechnical process starting from the maturation of females until the release of juveniles into a natural water area has been traced. Researches on the reproductive females included a comparative study of the size-weight characteristics, gamete-somatic index, and fecundity in both absolute and relative values as well as a response to hormonal simulation/treatment. The quality of offspring was evaluated by fish cultural and biological indicators of eggs, larvae and fries. The Persian (Kura) sturgeon natural population's off spring was served as control.

\section{Results and Discussion}

The global practice of fresh-water aquaculture proves a possibility of the maintenance and growing of sturgeon fishes in artificial conditions [3,4,6,7,14-16]. The principle of a bundling of maternal stock of sturgeon fish from spawn up to spawn is based on selection of elite posterity with the subsequent growing within 8-10 years up to mature sires. On the basis of posterity of artificial generation the recovery-maternal stock of sturgeon fish is formed with the purpose of reception of own sires on Khylly Sturgeon Hatchery since 2004 [9,8]. At the moment ten-year old- (400 pieces), nine-year old- (250 pieces), eight-year old- (200 pieces), seven-year old- (1200 pieces), six-year old- (500 pieces), five-year old - (500 pieces) Persian sturgeons (A.persicus) and different-years old Persian sturgeon (A.persicus), starred sturgeon (A.stellatus) and Kura-river ship (A.nudiventris) (more than 1000 pieces) of industrial manufacture are grown as an experiment in conditions of the Khylly Sturgeon Hatchery. Additionally, some ten of specimen of Siberian sturgeon (A.baerii), sterlets (A.ruthenus), beluga (Huso huso), besters (H.huso $x$ A.ruthenus) and Russian sturgeons (A.gueldenstaedtii) are grown as an experiment in the Khylly Sturgeon Hatchery. The general quantity of recovery-maternal stock of different kinds of sturgeon fish on Khylly Sturgeon Hatchery constitutes about 5000 specimens. The dynamics of development of young sturgeons grown in Khylly Sturgeon Hatchery since 2004 up to five-year age is shown at the Figure 1.

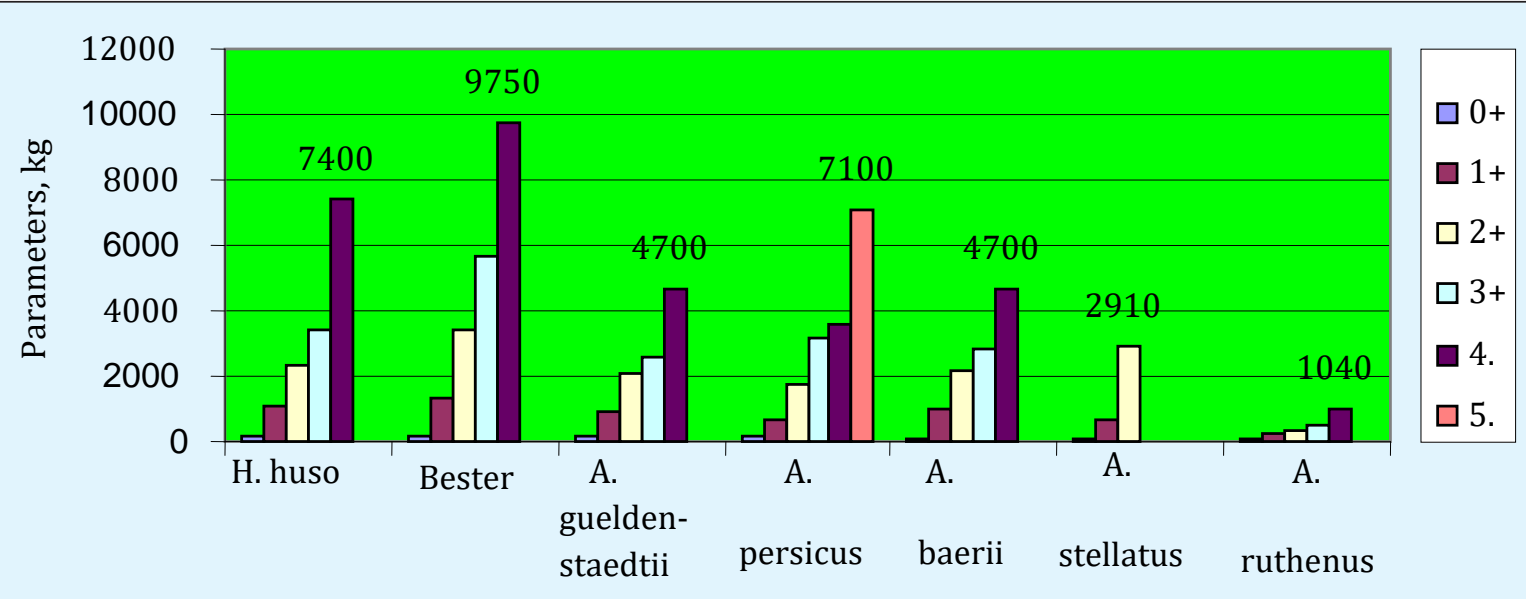

Figure 1: The dynamics of development of young sturgeons grown in the Khylly Sturgeon Hatchery since 2004. 
It is necessary to note that ecological conditions at growing of young fish and adult forms of sturgeon fish in pools radically differ from conditions in which their various stages of ontogenesis passed during many millions years of evolution. For this reason the long maintenance of young fishes and adult forms of sturgeon in the closed space, that is in ecologically impoverished environment, can lead to simplification of their behavioral reactions, to decrease in impellent activity, formation of the certain stereotype of food behavior, so, to serious changes in functioning of various physiological systems [17-19].

In 2012 based on these studies on the definition of sex and stage of maturity of the sturgeon broodstock by ultrasonic diagnosis we were able to identify several females of Persian (Kura) sturgeon from the broodstock of the generation 2004, the state of maturity of the gametes were at III-IV and at IV unfinished stages of development (Table 1).

\begin{tabular}{|c|c|c|c|c|c|c|c|c|c|c|}
\hline \multirow{2}{*}{ Species of sturgeons } & \multirow{2}{*}{$\begin{array}{c}\text { Years of getting } \\
\text { fries }\end{array}$} & \multirow[t]{2}{*}{ Sex } & \multicolumn{6}{|c|}{ Stage of maturity } & \multicolumn{2}{|c|}{$\begin{array}{c}\text { The total number of } \\
\text { sturgeon fishes }\end{array}$} \\
\hline & & & I & II & III-III & III & III-IV & IV & & \\
\hline \multirow{2}{*}{$\begin{array}{l}\text { Acipenser } \\
\text { persicus }\end{array}$} & \multirow{2}{*}{2004} & $\hat{0}$ & & 16 & 3 & 5 & 3 & 1 & 28 & \multirow{2}{*}{47} \\
\hline & & 우 & & 10 & 4 & 3 & 1 & 1 & 19 & \\
\hline \multirow{2}{*}{$\begin{array}{c}\text { Acipenser } \\
\text { gueldenstaedtii }\end{array}$} & \multirow[b]{2}{*}{2005} & $\hat{0}$ & & & & & 1 & & 1 & \multirow[b]{2}{*}{3} \\
\hline & & q & & & & & 1 & 1 & 2 & \\
\hline \multirow{2}{*}{$\begin{array}{c}\text { Acipenser gueldenstaedtii } \\
\text { x A. baerii }\end{array}$} & \multirow[b]{2}{*}{2005} & $\hat{0}$ & & & & 1 & 2 & & 3 & \multirow[b]{2}{*}{7} \\
\hline & & q & & & & 2 & 2 & & 4 & \\
\hline \multirow{2}{*}{$\begin{array}{l}\text { Acipenser } \\
\text { stellatus }\end{array}$} & \multirow{2}{*}{2006} & $\sigma^{\lambda}$ & & 1 & 1 & 2 & 2 & & 6 & \multirow{2}{*}{10} \\
\hline & & q & & 1 & 1 & 2 & & & 4 & \\
\hline \multirow{2}{*}{$\begin{array}{l}\text { Acipenser } \\
\text { ruthenus }\end{array}$} & \multirow{2}{*}{2005} & $\hat{0}$ & & 1 & 1 & & & & 2 & \multirow{2}{*}{2} \\
\hline & & q & & & & & & & & \\
\hline \multirow{2}{*}{ Huso huso } & \multirow{2}{*}{2005} & $\hat{0}$ & & 1 & & & & & 1 & \multirow{2}{*}{1} \\
\hline & & 우 & & & & & & & & \\
\hline
\end{tabular}

Table 1: Results of ultrasound diagnosis of sex and maturity stages of gonads of broodstock sturgeon in Khylly Sturgeon Hatchery of Azerbaijan (2012).

These females were replaced in a separate tank for the purpose of formation of reproductive females at the hatchery. So, creation of sex in sturgeon having no signs of external dimorphism at early ages and the reproductive run by using the non-invasive diagnostic methods of the maturity stage and implementation of these works according to required rules may be used in sturgeon fish farms of our republic and for commodity fish products.

In the 2013 year during the hatchery season after previewing reproductive females by diagnostic ultrasound intramuscular injections of aqueous suspension acetone-dried sturgeon pituitary. The duration of maturation of reproductive females after hormonal injection was 30-32 hours.

The average fecundity of two females was 131,150 of eggs. The number of eggs in $1 \mathrm{~g}$ sample amounted to 52 and 53 pieces, respectively. The incubation of sturgeon eggs took place in the individual "Osetr" incubation unit at a water temperature of $18,0-18,5^{\circ} \mathrm{C}$. The incubation period was 4,5 days. The percentage of eggs development determined at the stage of the small yolk tube (17 th stage) was 90.4 and $88.5 \%$, respectively (Table 2).

\begin{tabular}{|c|c|c|c|c|c|c|c|}
\hline \multirow{2}{*}{$\begin{array}{c}\text { Number } \\
\text { of fish }\end{array}$} & \multirow{2}{*}{$\begin{array}{c}\text { Length } \\
\mathrm{L}, \mathrm{cm}\end{array}$} & \multirow{2}{*}{$\begin{array}{c}\text { Weight, } \\
\text { кg }\end{array}$} & \multicolumn{2}{|c|}{ A number of eggs } & \multirow[b]{2}{*}{ Eggs sample, $1 \mathrm{~g}$} & \multirow[b]{2}{*}{ Fecundity thousand units } & \multirow[b]{2}{*}{$\%$ of fertilization } \\
\hline & & & kg & GSI $^{*} \%$ & & & \\
\hline 1 & 126 & 12,8 & 2,7 & 21,1 & 52 & 140400 & 90,4 \\
\hline 2 & 124 & 11,5 & 2,3 & 20,0 & 53 & 121900 & 88,5 \\
\hline
\end{tabular}

Table 2: Fish cultural and biological indicators of reproductive the Kura (Persian) sturgeon females. 


\section{Journal of Ecology \& Natural Resources}

\section{The Gonadosomatic Index}

The duration of the early ontogenesis of the experimental and control larvae was similar and was made up 8 days at the water temperature from $18.5^{\circ} \mathrm{C}$ to $19.5^{\circ} \mathrm{C}$. The onset of transition of larvae to active exogenous feeding was determined by their behavior, the release of melanin and the flow rate of the yolk mass, which by this time accounted for both versions $91.8 \%$.

During the transition to active feeding the larvae length increased up to $19.5 \mathrm{~mm}$ (experience) and 20.0 $\mathrm{mm}$ (control), the weight of larvae increased respectively to $38.0 \mathrm{mg}$ and $42 \mathrm{mg}$. The average daily growth rate on length of larvae in the experimental and control options amounted to 6.7 and $7.0 \%$ by weight $9.6 \%$ and $12.0 \%$, respectively. The survival rate of larvae switched to active feeding averaged $86.5 \%$ (experience) and $92.5 \%$ (control) with the standard index of $90 \%$. The obtained offspring subsequently reared in plastic basins and after reaching the standard sample of $(1.0 \mathrm{~g})$ were released into the Kura River's estuary $[20,21]$.

The results of growing out of juveniles were assessed by using the method of total enumeration. The survival rate of fingerlings in the basins of stocking larvae averaged $67.4 \%$. On separate basins this index varied from $64.5 \%$ to $73.6 \%$. For the offspring obtained from fish of the natural complex, it is equal to $72.4 \%$ (standard - 70\% - the temporary biotechnology standards for hatcheries of Azerbaijan 2007).

The analysis of fish breeding and biological indicators of hatchery-reared juveniles showed that the development of produced fry using reproductive females from broodstock was in compliance with the norm. Some of hatchery-reared fingerlings were kept at the hatchery with the view of further studying their morphological and biological and physiological features.

Thus, in fish cultural practices of Azerbaijan for the first time hatchery-reared broodstock females of the Persian (Kura) of sturgeon raised "from eggs" at the hatchery were used. These data indicate the prospects of the formation of the reproductive stage of various species of sturgeon at hatcheries. The creation of reproductive broodstock at sturgeon hatcheries will allow conservation of the sturgeon gene pool and expanding opportunities of their artificial reproduction to be released into natural water bodies.

\section{References}

1. Bemis WE, Kynard B (1997) Sturgeon rivers: an introduction to acipenseriform biogeography and life history. Environ Biol Fishes 48(1-4): 167-183.

2. Birstein VJ, Bemis WE (1997) How many species are there within the genus Acipenser? Environ Biol Fishes 48(1-4): 157-163.

3. Chebanov MS, Galich EV, Chmirh Yu N (2004) A guide on breeding and growing of sturgeon fishes. "Rosinformagrotekh", Moscow, pp: 147.

4. Chebanov MS, Galich EV (2010) Ultrasound diagnostics of sturgeons. "Prosveshchenie-Yug", Krasnodar, pp: 134.

5. Hajiyev RV, Kasimov R, Yu (2005) Sturgeon and salmon of Kura-Caspian region, their biological and ecological groups and physiological features. Zardabi, Baku, pp: 249.

6. Popova AA, Piskunova LV, Shevchenko VN (2004) Biological and technological regalements' of formation and the maintenance of maternal stocks of the sturgeon and beluga in conditions of Sturgeon Fish Hatchery in the delta of Volga. Piscicultural researches on Caspian Sea: Results of scientific research works for 2003, Astrakhan pp: 496-502.

7. Popova AA, Krupi VA, Chernova PV, Daudova GP (2007) The state of reproductive potential of the Volga-Caspian sturgeons under present conditions. The International Scientific and Practical Conference, Astrakhan pp: 258-260.

8. Mamedov Ch A, Hajiyev RV, Akhundov MM (2009) New technologies for sturgeon-breeding in Azerbaijan. "Science", Baku, pp: 260.

9. Mamedov Ch A, Salmanov ZS (2009) Aquaculture in Azerbaijan: Pool method rearing of sturgeon fishes and their repair-maternal stock in Khylly Sturgeon Hatchery. The Proceedings of the VI International Symposium on Sturgeon. Wuhan pp: 208-210.

10. Mamedov Ch A (2011) Morfophysiological and hematological features of recovery-maternal stock of sturgeon fish rearing in sturgeon fish hatchery of Azerbaijan. The Proceedings of the V International Conference. Belgrade pp: 258-260. 


\section{Journal of Ecology \& Natural Resources}

11. Mamedov Ch A (2012) The Results of experimentalindustrial works on Formation of reproduction Stock of Sturgeons in the conditions of the Aquaculture of Azerbaijan. Proceedings Azerbaijan National Academia Sciences: biological and medical sciences 67: 43-47.

12. Ivanova NT (1983) The atlas of blood cells of fish. "Leqkaya i pishevaya Promishlennost", Moscow, 184 pp.

13. Dettlaff TA, Ginsburg AS, Schmalhausen OI (1981) Development of sturgeon fishes. "Nauka", Moscow, pp: 223.

14. Stroganov NS (1968) Acclimatization and cultivation of sturgeon fish in ponds. "Moscow University", Moscow, pp: 377.

15. Smolyanov II (1987) Technology of formation and operation maternal stock of the Siberian sturgeon in warm-water facilities, "VNIIPRX", Moscow, pp: 33.

16. Cotenev BN, Bursev IA, Nikolayev AI, Dergalieva JT (2005) Strategy of preservation of sturgeon fish. Pisciculture and fishery 1: 10-13.
17. Arlati G, Bronzi P (1995) Sturgeon farming in Italy. The Proceedings of the II International Symposium on Sturgeon. Moscow pp: 321-332.

18. Chebanov MS, Rosenthal H, Gessner J, Van Anrooy R, Doukakis $P$, et al. (2011) Sturgeon hatchery practices and management for release - Guidelines. FAO Fisheries and Agriculture Technical Paper No 570. Ankara, FAO, pp: 110.

19. Mamedov Ch A, Akhundov MM, Hajiyev RV (2013) Definition of sex and maturity stage of recoverymaternal stock of sturgeon fish by the ultra sound method. The Proceedings of the Azerbaijan Institute of Zoology 31: 82-89.

20. Mamedov Ch A, Akhundov MM, Hajiyev RV (2014) Reproductive females of the persian sturgeon (Acipenser persicus) raised "from eggs" in the hatchery of Azerbaijan. The International Symposium on Fisheries and Aquatic sciences, Trabzon pp: 283284.

21. Podushka SB, Chebanov MS (2007) Caviar and sturgeon commodity in China. In Scientific and Technical Bulletin of Ichthyology Department of INENKO, St. Petersburg 13: 5-15. 